\title{
Hydrothermal Synthesis of Ammonium Aluminum Carbonate Hydroxide (AACH) Nanoplatelets and Nanofibers $\mathrm{pH}$-Controlled Morphologies
}

\author{
XueHui Li \\ State Key Laboratory of Heavy Oil Processing, Key \\ Laboratory of Catalysis CNPC \\ China University of Petroleum \\ Qingdao, Shandong, China, 266555 \\ 1xhhmx@163.com
}

\author{
Zhe Tang \\ State Key Laboratory of Heavy Oil Processing, Key \\ Laboratory of Catalysis CNPC \\ China University of Petroleum \\ Qingdao, Shandong, China, 266555
}

\author{
YongMing Chai \\ State Key Laboratory of Heavy Oil \\ Processing, Key Laboratory of \\ Catalysis CNPC \\ China University of Petroleum \\ Qingdao, Shandong, China, 266555
}

\author{
RuiYu Zhao \\ State Key Laboratory of Heavy Oil \\ Processing, Key Laboratory of \\ Catalysis CNPC \\ China University of Petroleum \\ Qingdao, Shandong, China, 266555
}

\author{
Chenguang Liu \\ State Key Laboratory of Heavy Oil \\ Processing, Key Laboratory of \\ Catalysis CNPC \\ China University of Petroleum \\ Qingdao, Shandong, China, 266555
}

\begin{abstract}
NH}_{4} \mathrm{Al}(\mathrm{OH})_{2} \mathrm{CO}_{3}$ precursors were prepared using $\mathrm{Al}\left(\mathrm{NO}_{3}\right)_{3}$ and $\mathrm{NH}_{4} \mathrm{HCO}_{3}$ as raw materials. The structural, morphological, and porous properties of the materials were investigated by BET, X-ray Diffraction (XRD), and Scanning Electron Microscope (SEM).The morphology and aspect ratios of resulting AACH nanoparticles were significantly influenced by the $\mathrm{pH}$ values in the preparation of solid precipitates. There were two kinds of morphology present, nanofibers and nanoplates. After thermal treatment at $550{ }^{\circ} \mathrm{C}$ in air for 4 hours, the morphologies of the nanostructures werewell preserved while the crystal structure was converted to $\gamma$-alumina.
\end{abstract}

Keywords-Ammonium Aluminum Carbonate Hydroxide; pH values; morphology

\section{INTRODUCTION}

Alumina has received special attention due to their thermal and chemical stability, high specific surface area, surface acidity, low cost and their potential in many applications[1] such as electronics, metallurgy, optoelectronics ,fine ceramic composites and catalyst supports[2,3,4,5]. The properties of $\mathrm{Al}_{2} \mathrm{O}_{3}$ are determined predominantly by crystal structure, composition, particle size and morphology. Therefore, the synthesis of $\mathrm{Al}_{2} \mathrm{O}_{3}$ with well controlled composition, size and morphology is of great significance for their applications[6].

This word was supported by the National Basic Research Program of China (No.2010CB226905) and the National Natural Science Foundation, China (No.21006128) and Specialized Research Fund for the Doctoral Program of Higher Education, (No.20100133120007) and Shandong Provincial Natural Science Foundation of China (ZR2011BQ002) and the Fundamental Research Funds for the Central Universities.
Presently, a lot of work studied the preparation of the morphology-controlled alumina via a AACH precursor due to its special crystal structure[7,8,9,10], which are benefits to the preparation of the morphology-controlled and mesoporesremained $\mathrm{Al}_{2} \mathrm{O}_{3}$ products. In the present work, we study the effect of $\mathrm{pH}$ values on Ammonium aluminum carbonate hydroxide synthesised by hydrothermal homogeneous precipitation methord. The $\mathrm{pH}$ value plays a key role on the morphology and textural porperties of $\mathrm{AACH}$ precursor and alumina.

\section{EXPERIMENTAL}

\section{A. Material Synthesis}

The synthesis of alumina precursors and samples was conducted using a hydrothermal homogeneous precipitation methord. All regents are analytical-grade. In a typical synthetic procedure, a certain amount of $\mathrm{Al}\left(\mathrm{NO}_{3}\right)_{3} \cdot 9 \mathrm{H}_{2} \mathrm{O}$ was added to $100 \mathrm{~mL}$ deionized water under vigorous stirring, then $2.0 \mathrm{~mol} / \mathrm{mL} \mathrm{NH}_{4} \mathrm{HCO}_{3}$ solution was added slowly. At last, ammonia solution was added into the mixture until $\mathrm{pH}$ value of the mixture was $7.0 \sim 11.0$. Then it was kept in an Electric Water Bath at $65{ }^{\circ} \mathrm{C}$ to allow crystallization for $24 \mathrm{~h}$. The product was collected by centrifugation, washed with distilled water and absolute ethanol several times to remove the impurities, and finally dried at $80{ }^{\circ} \mathrm{C}$ in an oven for $24 \mathrm{~h}$. The samples were denoted as (see Table 1). 
TABLE I. THE EFFECT OF PH VALUES ON PREPARING DIFFERENT ALUMINA NANOSTRUCTURE SAMPLES

\begin{tabular}{|c|c|c|c|}
\hline \multirow{2}{*}{ Sample } & \multicolumn{3}{|c|}{ Materials } \\
\cline { 2 - 4 } & $\begin{array}{c}\text { Aluminum salts } \\
(\mathbf{m o l} / \mathbf{m L})\end{array}$ & $\begin{array}{c}\mathbf{N H}_{4} \mathrm{HCO} \\
3 \\
(\mathbf{m o l} / \mathbf{m L})\end{array}$ & $\begin{array}{c}\boldsymbol{p H} \\
\text { values }\end{array}$ \\
\hline a & $\begin{array}{c}\mathrm{Al}\left(\mathrm{NO}_{3}\right)_{3} \cdot 9 \mathrm{H}_{2} \mathrm{O} \\
0.2\end{array}$ & 2.0 & 7.0 \\
\hline b & $\begin{array}{c}\mathrm{Al}\left(\mathrm{NO}_{3}\right)_{3} \cdot 9 \mathrm{H}_{2} \mathrm{O} \\
0.2\end{array}$ & 2.0 & 9.0 \\
\hline c & $\begin{array}{c}\mathrm{Al}\left(\mathrm{NO}_{3}\right)_{3} \cdot 9 \mathrm{H}_{2} \mathrm{O} \\
0.2\end{array}$ & 2.0 & 11.0 \\
\hline
\end{tabular}

TABLE II. TeXtural Properties of SOME REPRESENTATIVE SAMPLES CALCINED AT $550^{\circ} \mathrm{C}$

\begin{tabular}{|c|c|c|c|}
\hline \multirow{2}{*}{$\begin{array}{c}\text { Sample } \\
\text { s }\end{array}$} & $\begin{array}{c}\text { Textural Properties } \\
\text { BET specific } \\
\text { surface } \\
\text { area }\left(\mathbf{m}^{\mathbf{2}} \cdot g^{-1}\right)\end{array}$ & $\begin{array}{c}\text { Pore } \\
\text { volume }(\mathbf{m L} \cdot \\
\left.\boldsymbol{g}^{-1}\right)\end{array}$ & $\begin{array}{c}\text { Averag } \\
\text { e Pore } \\
\text { Size }(\mathbf{n m} \\
)\end{array}$ \\
\hline a & 257.03 & 0.86 & 12.67 \\
\hline b & 232.82 & 0.51 & 8.69 \\
\hline c & 310.43 & 1.05 & 10.77 \\
\hline
\end{tabular}

\section{B. Characterization}

X-ray powder diffraction (XRD) analysis was carried out with a PANalytical X'Pert PRO MPD diffractometer using a $\mathrm{Cu} \mathrm{K} \alpha$ radiation $(\lambda=1.54060 \AA)$ operating at $40 \mathrm{kV}$ and $40 \mathrm{~mA}$. A scanning electron microscope (SEM) (Hitachi S-4800) coupled with an electron dispersive X-ray (EDX) was used to perform elemental analysis. The $\mathrm{N}_{2}$ adsorption and desorption isotherms were measured on a Micromeritics Tristar 3000 instrument. Specific surface area determination was made using the BET isotherm. Fresh samples were vacuum dried before the adsorption measurement.

\section{RESULTS AND DisCUSSION}

\section{A. Effect of the pH values on the morphology of $A A C H$ products}

The crystalline phase of the as-prepared samples was identified by powder X-ray diffraction. Curve (a), (b) and (c) in Fig. 1 shows the typical XRD patterns of the as-synthesized samples prepared at $80{ }^{\circ} \mathrm{C}$ for $24 \mathrm{~h}$ at $\mathrm{pH} \approx 7.0,9.0$, and 11.0 respectively. All the diffraction peaks can be identified as the crystalline AACH (JCPDS card 042-0250). The chemical reaction occurs as follow[11]:

$$
\mathrm{Al}^{3+}+4 \mathrm{NH}_{4} \mathrm{HCO}_{3}=\mathrm{NH}_{4} \mathrm{AlO}(\mathrm{OH}) \mathrm{HCO}_{3} \downarrow+3 \mathrm{CO}_{2} \uparrow+\mathrm{H}_{2} \mathrm{O}+3 \mathrm{NH}_{4}^{+}
$$

The $\mathrm{pH}$ value of the initial solution has great effect on the size and morphology of the hydrothermal products. The SEM images of precursors $\mathrm{a}, \mathrm{b}$ and $\mathrm{c}$, which are synthesized in different $\mathrm{pH}$ values are shown in Fig.1(B),(C),(D). The three precursor samples have different morphology. Which can be easily distinguished by SEM spectra. Samples (a) and (b) possess rod-like architecture with a diameter form $40 \mathrm{~nm}$ to $100 \mathrm{~nm}$, and the length form $300 \mathrm{~nm}$ to $700 \mathrm{~nm}$. The precursor particles become smaller as the $\mathrm{pH}$ values increased.

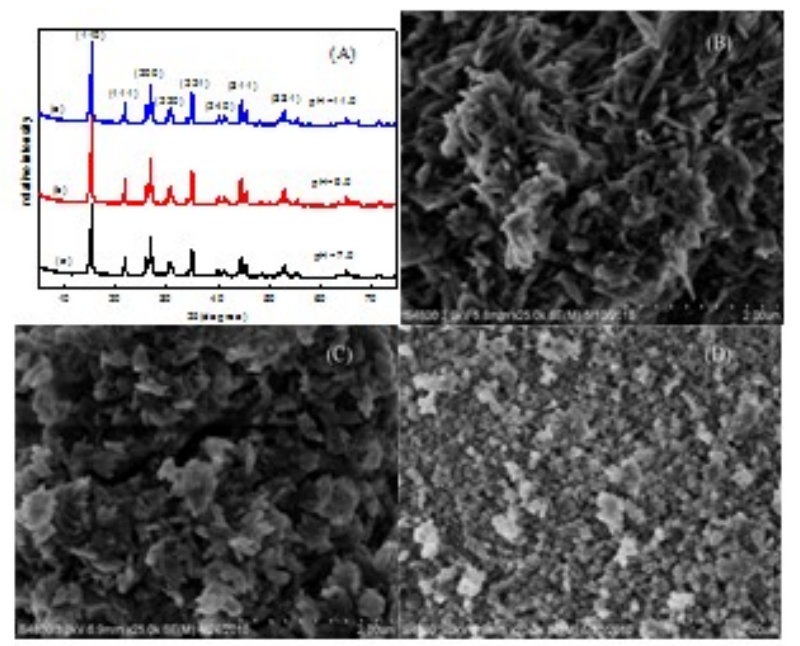

Figure 1. (A)X-ray diffraction patterns of AACH synthesized in different $\mathrm{pH}$ values and the SEM photographs of the samples (B) $\mathrm{pH}=7.0$, (C) $\mathrm{pH}=9.0$, (D) $\mathrm{pH}=11.0$.

B. Effect of the $p H$ values on textural properties and morphology of alumina

To investigate the specific surface area and porous nature of the $\gamma-\mathrm{Al}_{2} \mathrm{O}_{3}$ samples obtained by calcining at $550{ }^{\circ} \mathrm{C}$ for $4 \mathrm{~h}$, Brunauer-Emmett-Teller (BET) gas-sorption measurements were carried out. The structural parameters derived from these isotherms are summarized in Table 2. Specific surface area of sample (c) is higher $\left(310.43 \mathrm{~m}^{2} \cdot \mathrm{g}^{-1}\right)$ than sample (a)(257.03 $\left.\mathrm{m}^{2} \cdot \mathrm{g}^{-1}\right)$ and (b) $\left(232.82 \mathrm{~m}^{2} \cdot \mathrm{g}^{-1}\right)$ according to the decrease of particle size, and the sample (b) shows a minimum average pore size when $\mathrm{pH}=9.0$. Figure 2 shows the nitrogen adsorption-desorption isotherms of $\gamma-\mathrm{Al}_{2} \mathrm{O}_{3}$ samples (a),(b)and (c). It can be seen that all of these samples reveal a type-IV isotherm with an $\mathrm{H} 1$ hysteresis loop, indicating that they belong to mesoporous material. The well-developed H1 hysteresis loop in the case of sample(a),(b) and (c) is believed to be related to the capillary condensation in large pore channels with possible channel modulation[12]. The results of their BJH pore size distribution (Figure 2(A)) show the materials have uniform porous size distribution centered at ca. $4.2 \mathrm{~nm}$, which is consistent with their results of SEM. The capillary condensation steps for the samples ranging from (a) to (c) are shifted to different relative pressures, indicating an difference in the size of mesopores. As can be seen from these figures, the textural properties of $\gamma-\mathrm{Al}_{2} \mathrm{O}_{3}$ are highly dependent on the alumina precursors synthesised $\mathrm{pH}$ values. 


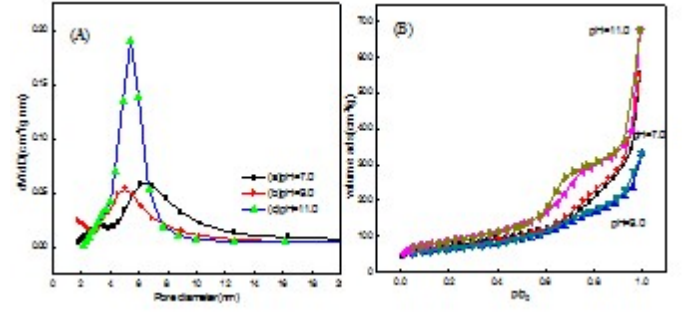

Figure 2. $\mathrm{N}_{2}$ adsorption-desorption isotherm, and pore size distribution for $\gamma$ $\mathrm{Al}_{2} \mathrm{O}_{3}$ prepared at different $\mathrm{pH}$ values

Figure 3 presents the SEM images of samples (a), (b), (c) alumina synthesized in different $\mathrm{pH}$ values. It can be seen that the sample (a) in Fig.3(A) are made of uniform microfibers with the length of about $300-500 \mathrm{~nm}$ and the width of less than $100 \mathrm{~nm}$.There are also some little patchs around the rod-like nanofibers, which were formed during the calcination process. Sample (b) present the same morphology as sample(a),but its overall dimensions was smaller. It is seen that the sample(c) exhibits a particle morphology with the aggregation of nanorod particles.
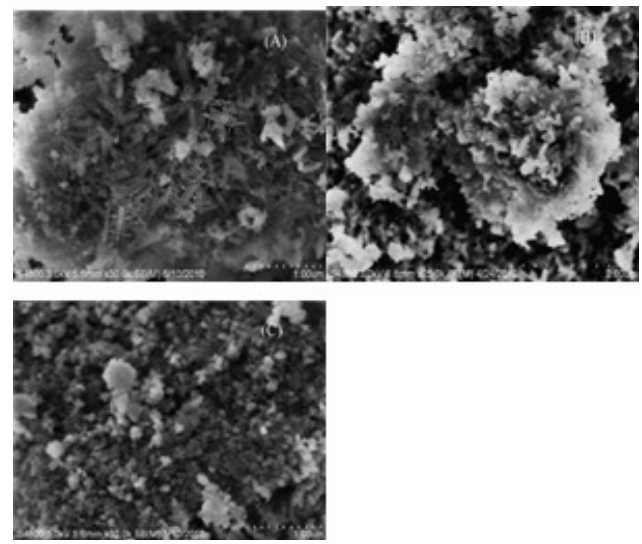

Figure 3. The SEM photographs of alumina synthesized in different $\mathrm{pH}$ values(A)pH=7.0,(B) $\mathrm{pH}=90,(\mathrm{C}) \mathrm{pH}=11.0$.

\section{CONCLUSION}

Ammonium aluminum carbonate hydroxide and $\gamma-\mathrm{Al}_{2} \mathrm{O}_{3}$ had been successfully synthesized by hydrothermal process of $\mathrm{Al}\left(\mathrm{NO}_{3}\right)_{3} \cdot 9 \mathrm{H}_{2} \mathrm{O}$ with the $\mathrm{NH}_{4} \mathrm{HCO}_{3}$. The study showed that the morphology and aspect ratios of resulting $\mathrm{AACH}$ nanoparticles were significantly influenced by the $\mathrm{pH}$ values. Nanofibers were synthesised at the $\mathrm{pH}=7.0$ and 9.0. While, nanoplates were synthesised at the $\mathrm{pH}$ value of 11.0. However, the detailed mechanism is not clear and still under way nowadays.

\section{REFERENCES}

[1] Guang-Ci Li, Yun-Qi Liu, , Li-Li Guan, Xiao-Fu Hu, Chen-Guang $\mathrm{Liu}$,"Meso/macroporous $\gamma-\mathrm{Al}_{2} \mathrm{O}_{3}$ fabricated by thermal decomposition of nanorods ammonium aluminium carbonate hydroxide," Materials Research Bulletin, vol.47,pp.1073-1079,2012

[2] P. G. Lucuta, J.D. Halliday B. Christian. "Phase evolution in $\mathrm{Al}_{2} \mathrm{O}_{3}$ fibre prepared from an oxychloride precursor." Journal of Materials Science,vol 27, pp.6053-6061,1992

[3] Lavaste.V., Berger, M.H., Bunsell, A.R., Besson, J. "Microstructure and mechanical characteristics of alpha-alumina-based fibres," Journal of Materials Science,vol 30, pp. 4215-4225, 1995

[4] Laurence Meaghera, George V. Franksb, Michelle L. Geea, Peter J. Scalesa, Interaction forces between $\alpha$-alumina fibres in aqueous electrolyte measured with an atomic force microscope. Colloids and Surfaces A: Physicochemical and Engineering Aspects, vol.146, pp. 123-137, 1999

[5] G. Tournier, M. Lacroix-repellin, G.M. Pajonk, S.J. Teichner, "Microporous Amorphous Alumina of a Zeolitic Type for Catalytic Reactions with Methanol," Studies in Surface Science and Catalysis,vol 31, pp.333-342, 1987

[6] Hui Liua, Hongjun Suna, Junqi Li, Xuanmeng He, Zhenfeng Zhu, “pHdependent formation of AACH fibers with tunable diameters and their in situ transformation to alumina nanocrystals with mesoporous structure," Advanced Powder Technology,vol. 23, pp.164-169,2012

[7] Muhammad Abdullah, Mazhar Mehmood, Jamil Ahmad,"Single step hydrothermal synthesis of 3D urchin like structures of AACH and aluminum oxide with thin nano-spikes," Ceramics International,vol 38 pp.3741-3745,2012

[8] Z. Zhang, T.J. Pinnavaia. "Mesostructured $\gamma$-Al2O3 with a lathlike framework morphology,"J. Am. Chem. Soc., vol.124, pp. 12294 12295,2002

[9] Z. Li, X. Feng, H. Yao, X. Guo. "Ultrafine alumina powders derived from ammonium aluminum carbonate hydroxide,'J. Mater. Sci., vol.39, pp. 2267-2269,2004

[10] Yong-Taeg O, Sang-Woo Kim, Dong-Chan Shin, "Fabrication and synthesis of $\alpha$-alumina nanopowders bythermal decomposition of ammonium aluminum carbonatehydroxide (AACH),"Colloids and Surfaces A: Physicochemical and Engineering Aspects,vol,313-314, pp. 415-418,2008

[11] Zhisen Wu, Youde Shen, Yan Dong, Jianqing Jiang, "Study on themorphology of $\alpha-\mathrm{Al}_{2} \mathrm{O}_{3}$ precursor prepared by precipitation method," Journal of Alloys and Compounds,vol 467, pp.600-604,2009

[12] Peidong Yang, Dongyuan Zhao, David I. Margolese, Bradley F.Chmelka, Galen D. Stucky, "Generalized syntheses of large-pore mesoporous metal oxides with semicrystalline frameworks,"Nature,vol.396,pp.152155,1998 . 